\title{
5:articulos
}

\section{La mirada lógica: En torno a la re-construcción de la identidad cultural de la ciudad histórica en clave historiográfica}

\author{
Belén Calderón Roca \\ Grupo de Investigación HUM 130. Universidad de Málaga
}

\section{RESUMEN}

En este trabajo analizaremos la importancia que los vestigios tangibles de la ciudad histórica (arquitectura vernácula) han adquirido como documentos para reconstruir la trama urbanística y para reconciliar interrelaciones entre comunidad y territorio, a través de las cuales, los valores se fabrican y re-construyen conforme a un sistema permanente de interacción. La principal aportación reside en plantear el estudio de la compleja red de significados que la ciudad histórica integra con una finalidad útil: incidir en la correcta resignificación de los valores culturales colectivos mediante un método sistemático y preciso, y fuente documental imprescindible: el conocimiento historiográfico-crítico.

PALABRAS CLAVE: Patrimonio Cultural/ Urbanismo/ Arquitectura/ Historiografía.

The Logical View. Around Re-Construction of Historic Town's Cultural Identity according Historiographical Code.

ABSTRACT

This work is about of the importance of the tangibles vestiges in the historical cities (autochthonous architecture) have acquired as documents for the reconstruction of the historical urban layout and to reconcile interconnections between community and territory, by means of them, the merits build and reconstruct themselves agreed with an interaction permanent system. The principal contribution resides in to pose the study of the complex mesh of meanings that the historical city composes with a useful purpose: insist in the correct meanings of collective cultural merits by means of a systematic and precise method, essential documentary source: the historiographyc-critical knowledge.

KEY WORDS: Cultural Heritage/ Town Planning/ Architecture/ Historiography.

\section{INTRODUCCIÓN.}

Gran parte de las ciudades históricas españolas son deudoras de acciones de destrucción y reconstrucción que se acometieron hasta la década de los setenta del siglo XX. En algunos casos, estas reconstrucciones significaron la fragmentación de la imagen urbana, la distorsión de la propia percepción e interpretación de la ciudad, así como la desvinculación y el desmembramiento del sentimiento de identificación de la comunidad con su territorio. En el caso concreto de Málaga, las primeras tentativas para recuperar un patrimonio urbano sumamente diverso, frágil y difuso, visi-

* CALDERÓN ROCA, Belén: "La mirada lógica: En torno a la re-construcción de la identidad cultural de la ciudad histórica en clave historiográfica", en Boletín de Arte, $\mathrm{n}^{\circ}$ 29, Departamento de Historia del Arte, Universidad de Málaga, 2008, págs. 437-453. 
blemente descontextualizado e infravalorado se pusieron en marcha en los años ochenta, siendo la década siguiente testigo de las primeras exploraciones realizadas en profundidad

\section{Ciudad histórica e identidad cultural.}

"La arquitectura es la escena fija de las vicisitudes del hombre; con toda la carga de los sentimientos de las generaciones, de los acontecimientos públicos, de las tragedias privadas, de los hechos nuevos y antiguos"1.

Popularmente, el valor más importante que ha caracterizado a la ciudad histórica es aquel habitualmente centrado en el testimonio material, constituido principalmente por bienes de carácter inmueble que cristalizando en la arquitectura ejemplar y en la trama urbana de la ciudad, constituyen un hábitat complejo del que forman parte piezas materiales testimoniales, verdadero documento de transmisión de la identidad individual y colectiva de los pueblos. Sin embargo, esas piezas materiales forman parte de una unidad global que integra una serie infinita de situaciones y relaciones numerosas, frecuentes y densas, e implican una intrincada red de movilidad y encuentros. Este complicado organismo denominado ciudad histórica únicamente se convertirá en documento capaz de expresar un mensaje si las condiciones contextuales son las necesarias.

La arquitectura vernácula (arquitectura espontánea, rural, industrial y gran parte de la doméstica) ha sufrido descrédito durante largo tiempo, ya que un vasto sector de la ciudad histórica ha permanecido postergado en esa especie de limbo cismático por no considerar que sus valores estaban a la altura de las piezas monumentales. La ciudad histórica constituye un organismo vivo, desarrollado mediante un proceso continuo de establecimiento de diversos asentamientos humanos socialmente organizados. La ciudad asentada en el lugar, adecua un espacio artificial en el cual toda sociedad -una vez alcanzado un suficiente grado de diferenciación respecto de los grupos sociales precedentes- intenta rubricar el testimonio de ambiciones y aspiraciones específicas, tanto de carácter individual como colectivo de una época determinada, ratificando una autoreafirmación a través de la representación de hitos arquitectónicos. El testimonio aportado por la arquitectura es válido precisamente por las continuas transformaciones y adaptaciones sufridas a lo largo del tiempo y de los sucesos del progreso histórico-social. Cuanto más intensas son las tendencias a una posible continuidad de la presencia física, mayor significado y valor cultural entrañará la ciudad. La repetición o superposición de tipologías específicas establece relaciones urbanas precisas, esta urdimbre dialéctica que preside la transición de la referencia de una arquitectura aislada a la referencia de la ciudad como esencia simbólica propia, constituye la raíz del significado de las ciudades. La arqui-

${ }^{1}$ ROSSI, A.: La arquitectura de la ciudad, Barcelona, Gustavo Gili, 1971, pág. 62. 
tectura vernácula (“Arquitectura Típica Regional”) como ya apuntó el maestro Chueca Goitia, es una manifestación autóctona del saber de los pueblos, y el mismo pueblo fue el que la dotó de vida al servirse de ella para sus necesidades, al otorgarle una función².

En muchas ocasiones, edificios con notable interés cultural han asumido durante determinados períodos funciones significativas, pero a excepción de los grandes hitos monumentales la mayoría de las veces esta significación no ha traspasado el ámbito de lo íntimo y resulta muy difícil transmitirlo a la totalidad de la sociedad, a menudo desconocedora de su herencia patrimonial más cercana. Es por ello que su trascendencia y reconocimiento a nivel popular, es menor, pero no por ello su valor cultural, así como su dignidad y el respeto profesado hacia ellos deban de ser nimios. Sin embargo, el Patrimonio de las ciudades históricas (patrimonio urbano) se compone de otros elementos que van más allá de los meramente tangibles, más allá del medio físico. El acervo patrimonial urbano viene además engendrado por las gentes, las costumbres, las supersticiones, las creencias, el folklore, las expresiones de los seres humanos, los testimonios y los silencios, que a veces ilustran un recorrido lúcido y atractivo, mientras que otras nos muestran un camino difuso y remoto.

\section{La mirada lógica. A propósito del método historiográfico.}

"Son muchos los modos de contar una ciudad"3.

A menudo observamos, asimilamos e interpretamos nuestras ciudades históricas de una manera inadecuada. Pretendemos decir que nuestro modo de ver no es ciertamente objetivo, ya que los condicionamientos de nuestra herencia cultural, las propias sugestiones del individuo, el gusto personal o la predisposición de ánimo con que ejercemos la contemplación, se configuran como agentes responsables directos del impacto que provocan en nosotros los objetos percibidos. Estas circunstancias nos obligan a percibir las emociones que desprende el lugar polarizando nuestra sensibilidad e inundándola de imágenes, obligándonos a construir nuestra propia identidad cultural.

La identidad cultural de una comunidad que se reconoce en su territorio, se define como el conjunto de recuerdos del pasado que permanecen presentes en la conciencia colectiva; un flujo permanente que abraza toda actividad social desde su inicial asentamiento, crecimiento, evolución y establecimiento en un determinado

2 CHUECA GOITIA, F.: La destrucción del legado urbanístico español, Madrid, Espasa-Calpe, 1977, págs. 89-93.

3 CAMACHO MARTÍNEZ, R.: "Apuntes sobre la planimetría de Málaga. Para una lectura de la ciudad en la Edad Moderna", en ASENJO RUBIO, E. y CAMACHO MARTÍNEZ, R. [coors. y eds.]: Las ciudades históricas del Mediterráneo. Fuentes literarias y representación gráfica, Málaga, Universidad, Ayuntamiento, Colegio de Ingenieros de Caminos, Canales y Puertos. Demarcación de Andalucía, 2008, pág. 99. 
ambiente, reflejándose en las creaciones materiales en las que la sociedad trata de reconocerse. Dicha identidad cultural se funda necesariamente sobre significados, comportamientos y actitudes comunes ante vivencias semejantes en las que los actores-espectadores de dicha comunidad se ven envueltos o afectados, y va nutriéndose progresivamente de recuerdos que la propia comunidad va incorporando paulatinamente a su propia memoria. En cualquier caso, nuestra mirada es consecuencia del modo de mirar que ejercemos, haciendo uso de las herramientas habituales que conocemos y de las que disponemos, de las que somos capaces de poner en práctica. ¿Sería ésta una mirada lógica? Lógica sí en cuanto razonable, como consecuencia natural de una usanza. No obstante, no podemos considerarla lógica en la medida de que no se trata de un aprendizaje producto de un método de razonamiento dialéctico. La realidad histórica es objeto de la investigación y del rol cognoscitivo y creativo del intelecto del historiador ${ }^{4}$. Llamamos a este proceso dialéctica. La dialéctica presupone que la realidad histórica en su riqueza, complejidad y heterogeneidad, y concatenación de la reconstrucción de los hechos, sea una forma de conocimiento y una aproximación a la verdad absoluta a través de la verdad aproximada en forma de hipótesis. Proponemos la aprehensión de una realidad reconstruyendo los sucesos o acontecimientos de un modo en el que el nivel de concordancia entre la reconstrucción del hecho histórico y la realidad histórica exista en función de la objetividad del historiador, lo que constituye el último criterio de veracidad 5 .

Cuando hablamos de método, nos referimos a un modo de proceder que surge de la aplicación de una determinada concepción de la historia. La metodología o método en este caso, no se comprende sin la teoría de la que parte el historiador, cuya labor es precisamente la conformación de las técnicas de trabajo que le serán útiles en su tarea heurística, para tomar conciencia de los problemas que pueden plantear las fuentes y aplicar el método crítico adecuado que verifique su autenticidad, apreciar su contenido de acuerdo con la época y el lugar preciso en que se inscriben dichas fuentes, así como construir las interpretaciones de los hechos con validez universal. Dicho método deberá estar siempre en función de la teoría que el historiador profesa mediante un contacto irremisible con el presente, puesto la Historia que no puede ser plenamente ciencia más que si deja de encerrarse en el pasado y únicamente la Teoría de la Historia aparecerá como válida en la medida que nos sirva para comprender el presente 6 .

En las últimas décadas el Patrimonio Cultural ha constituido un ámbito de investigación preferente en el campo de la Historia o de la Historia del Arte. No obs-

\footnotetext{
4 Para una óptima comprensión de este trabajo, puntualizamos que se utilizará el término "historiador" para referirnos de un modo concreto al historiador del arte en su relación con el Patrimonio Cultural, y asimismo, la expresión "realidad histórica" (objeto de investigación afrontado por el historiador) se reconocerá como ciudad histórica.

5 TOPOLSKI, Metodologia della ricerca storica, Bologna, II Mulino, 1975, pág. 257.

6 PAGÉS, P.: Introducción a la Historia. Epistemología, teoría y problemas de método en los estudios históricos, Barcelona, Barcanova, 1983, págs. 70-71.
} 
tante, al hablar de Patrimonio y Cultura podemos incurrir en considerarlas nociones análogas a causa de la polisemia de ambos términos. Para superar este escollo, expondremos que el adjetivo "cultural" viene a conferir carácter normativo e institucional al Patrimonio, siendo éste selección de un conjunto de bienes dotados de significados que son representativos de un pueblo. La cultura aparece por vez primera expresada como derecho colectivo reconocido en las constituciones democráticas de la segunda mitad del siglo XX. Su concepción antropológica es relativamente reciente y se relaciona con la impugnación de los modelos de gobierno decimonónicos. Desde que tuvieron lugar las revoluciones liberales y por influencia francesa, en el Estado Liberal ${ }^{7}$, la igualdad de derechos favorece el principio de que la plena realización de los seres humanos sólo es posible lograrse mediante la interacción de los individuos que pertenecen a una misma cultura y que comparten análogos modos de entender su entorno ${ }^{8}$. En $1985^{9}$ la legislación adoptó la noción antropológica de la cultura, confiriendo legitimidad a todas las formas de organizar y simbolizar la vida social. A partir de este momento ya no se priorizan los Bienes Culturales generados por las clases hegemónicas, sino que la cultura popular y a las tipologías tradicionales del Patrimonio se incorporan nuevos conceptos como "intangible" o "inmaterial". Precisamente ese patrimonio intangible definido como: "todos aquellos objetos, elementos o prácticas costumbres y tradiciones que son características identificadoras de una sociedad, fruto de sus relaciones peculiares con el medio y la experiencia histórica"10, es el que es más dificultoso de percibir, aprehender, interiorizar y asimilar.

En el ámbito doctrinal, tras la inclusión de los entornos de los inmuebles protegidos por la legislación ${ }^{11}$, las nuevas tendencias científicas pretenden sustituir la importancia de los elementos tradicionales en la configuración y descripción del Patrimonio Cultural (es decir, los valores históricos o artísticos), por un nuevo factor: el territorio, en donde se imbrican los bienes de la cultura y de la naturaleza, convirtiéndose además en un instrumento de gestión del Patrimonio. Teniendo presentes estos presupuestos, el Patrimonio Urbano es definido inicialmente como una obra cultural

7 Tras la Revolución Francesa se generó una necesidad de erigir de un modo firme los presupuestos de libertad y revalidarlos en el proyecto de Código Civil de 1836, a través de una "sacralización del derecho de propiedad", partiendo de tres condiciones: un derecho libre, sin exclusiones, absoluto, sin limitaciones, e individual referido a las personas físicas. Vid. DÍEZ-PICAZO y GULLÓN, A.: Sistema de Derecho Civil, Madrid, Tecnos, 1984.

8 AGUDO TORRICO, J. y FERNÁNDEZ DE PAZ, E.: "Viejos y nuevos retos para el Patrimonio Cultural de Andalucia”, en HURTADO SÁNCHEZ, J. y FERNÁNDEZ DE PAZ, E. (eds.): La cultura andaluza en el umbral del siglo XXI, Sevilla, Ayuntamiento de Sevilla, 2001, págs. 113-141.

9 Hacemos referencia a la Ley 16/1985, de 25 de junio, del Patrimonio Histórico Español.

10 ESCALERA REYES, J.: "La Fiesta como Patrimonio", en PH Boletín del Instituto Andaluz de Patrimonio Histórico, año V, n² 21, Sevilla, 1997, págs. 53-57.

11 La institucionalización del término "entorno" no significa que sus límites hayan sido precisados: pueden incluirse en él solamente aspectos visuales y tangibles de aquello que rodea al hombre, o bien, elementos intangibles como la comunicación y aun, la misma cultura. Para mayor información vid. CASTILLO RUIZ, J. El entorno de los bienes inmuebles de interés cultural. Concepto, legislación y metodologías para su delimitación. Evolución Histórica y situación actual, Universidad de Granada, Instituto Andaluz de Patrimonio Histórico, Granada, 1997. 


2: artículos Belén Calderón Roca

articulada en el sistema global de un determinado pueblo que refleja su verdadera personalidad a lo largo de siglos de existencia, y es precisamente ésta su razón de ser. Aunque no se trata de algo connatural, sino de una construcción social cambiante a lo largo de la historia, la legitimación de la memoria colectiva de una determinada sociedad se verifica al compartir ésta, bien directa o indirectamente, los elementos que la misma sociedad construye por medio de una confrontación simbólica. Las recientes investigaciones sobre la manera en que se transmite el conocimiento demuestran que la confrontación simbólica es algo inevitable, si bien, desigual en diversos grupos de una misma sociedad ${ }^{12}$. Los criterios de selección de los elementos patrimoniales y de los hechos históricos vinculados a éstos nos remiten a una necesaria y específica instrumentación que permita descifrar significados y funciones. De otro modo, la argumentación interpretativa de los mismos sería imposible de realizar si no se contextualizase el proceso que ha tenido lugar durante la delimitación del hecho histórico ${ }^{13}$.

El método histórico inaugurado por Giovannoni en la primera mitad del pasado siglo para investigar sobre Historia de la Arquitectura ${ }^{14}$ ha generado una importante repercusión en la tradición historiográfica contemporánea, y aun hoy día no se pueden considerar conclusas las investigaciones sobre la obra de Giovannoni en el panorama actual, ya que los ecos de sus estudios se integran perfectamente en la tradición abrazada por las investigaciones sobre restauración de monumentos en segunda mitad del siglo XX. Desde sus primeros escritos Giovannoni establece dos premisas para un correcto estudio histórico de la arquitectura: la primera atañe a la especificidad del campo de los estudios, irreducible a dos estadios: por una parte, una valoración puramente visibilista de la realidad arquitectónica, con la enunciación de una singularidad, y por otra, la pluralidad de métodos con que esta realidad viene investigada, lo que es llamado por Giovannoni el sistema integralistico, resultante de entretejer varias competencias -entre ellas el método historiográfico-. Es de destacar la incidencia didáctica que el método utilizado giovannoniano ha tenido en la tradicional "deshistorización" de la praxis en el campo de la Historia de la Arquitectura, es decir, en la tradicional práctica de estudiar la arquitectura. La mayoría de autores abordaban la investigación de la obra arquitectónica esencialmente a través de un proceso de continua disección. Debido a su carácter entrópico trataban de clarificar cada detalle, ya que cuanto más descomponían los elementos en partículas simples, más fácilmente podían alcanzar su esclarecimiento ${ }^{15}$. Por el contrario, en el concre-

12 PRATS, LL.: Antropología y Patrimonio, Barcelona, Ariel, 1997.

13 FERRUELO MAGÁN, Y.: "Espacios, prácticas y bienes: La representación del Patrimonio desde una mirada antropológica", en ASENJO RUBIO, E. y CAMACHO MARTÍNEZ, R.: Las ciudades históricas del Mediterráneo. El sector turístico, la dinamización cultural y las nuevas tecnologías aplicadas al patrimonio cultural, Málaga, Universidad, Departamento de Historia del Arte; Junta de Andalucía, Delegación Provincial de Cultura, Programa "Euromed Heritage II: Patrimoines Partagés: Savoirs et savoir-faire apliques au patrimoine architectural et urbain des XIX-XX siècles en Mediterranée, 2006, pág. 80.

14 Vid. CALDERÓN ROCA, B.: "La gestión de la ciudad histórica en la Roma fascista 1: la instrucción sobre restauro urbano a través de la obra de Gustavo Giovannoni”, en Boletín de Arte $\mathrm{n}^{\circ} 28$, Departamento de Historia del Arte, Universidad de Málaga, 2007, págs. 253-277. 
to ejercicio histórico-crítico del método giovannoniano se estableció un efectivo procedimiento que integraba competencias y procedimientos permeables a las averiguaciones caso por caso, derivadas del análisis directo de la obra, instaurando de este modo un diálogo interpretativo entre el método empírico positivista y el modelo fenomenológico existencialista ${ }^{16}$. Giovannoni trató en definitiva, de conferir mayor base teórica a aquellos caracteres ya presente en la clásica técnica de hacer Historia de la Arquitectura meramente visual, pues siendo una ciencia humana resultaba imprescindible la circulación y confrontación permanente entre categorías generales y casos concretos, así como la verificación posterior de resultados ${ }^{17}$.

En la actualidad, la investigación de la obra arquitectónica se aborda mediante la confrontación directa con el texto y el estudio del contexto, pues éste último nos proporciona una historiografía respetuosa con los múltiples significados que la obra integra, y atiende además, a los mecanismos institucionales y administrativos, a la interacción de artistas, eruditos o mecenas, así como a la reconstrucción hipotética de situaciones culturales o de cualquier otra índole que propiciaron la génesis de la obra en cuestión. Partir del texto o del contexto no deben ser procedimientos excluyentes el uno del otro para abordar el estudio histórico-crítico de obra arquitectónica (ciudad histórica en nuestro trabajo). Sin embargo, en el caso de las ciencias humanas el orden de los factores sí puede afectar al producto, pues partir del texto o del contexto puede condicionar en grado el resultado final ${ }^{18}$. Al emprender el estudio desde el contexto nos embarcamos en una historiografía continuista que no será permeable a las singularidades concretas de la obra, así como de determinados sucesos determinados que podrían derivar en fisuras o rupturas de mensaje provocadas por una lectura plagada de lagunas que veces se torna inextricable, y por ende, se podría extraer una interpretación precaria y dudosa de la obra.

La "excavaciones documentales" que proponía Giovannoni planteaban considerar tanto el elemento contenedor, en ese caso la ciudad histórica, como los modelos historiográficos que a través de diferentes épocas han favorecido el conocimiento y la transmisión de información referente a dicha ciudad histórica. Este debate viene considerado hoy derivado de un contexto histórico bastante accidentado en el que la efervescencia de teorías omniscientes era una constante, pero en cualquier caso, nada obsoleto. Tanto entonces como ahora, en el empleo del método de indagación netamente documental, ningún documento prueba por sí sólo la existencia indiscutible de los hechos de un modo absoluto. La verdad susceptible de emanar dependerá de la habilidad y de la prudencia del historiador en la formulación de sus

15 ROCA DE AMICIS, A.: "Una tradizione storiografica oggi", en SETTE, M P. [a cura di]: Gustavo Giovannoni: Reflessioni agli albori del XXI secolo. Giornata di Studio dedicata a Gaetano Miarelli Mariani (1928-2002), Roma, Bonsignori Editore, 2005, pág.17.

16 ROCA DE AMICIS, A.: "Una tradizione... "op. cit., pág. 16

17 CALDERÓN ROCA, B.: "Más allá del patrimonio arquitectónico: La ciudad histórica como imagen simbólica de una identidad cultural en construcción”, en Isla de Arriarán, $n^{\circ} 29$, Málaga, Asociación Cultural Isla de Arriarán, 2008 (en prensa)

18 ROCA DE AMICIS, A.: Ibídem. 
hipótesis, así como en la calificación del hecho, peldaño indispensable para aprehender el pasado: "Puesto que el pasado no es algo dado que podemos aprehender empíricamente mediante percepción directa (ex hipotesi)"19. En virtud de esta afirmación, la construcción de hechos de conocimiento científico está epistemológicamente condicionada y exigida por la capacidad de configurar un sistema de principios generales que formen un conjunto coherente y susceptible de ordenar los datos asignables estableciendo una equivalencia entre el sistema de tales principios y la estructura de los que se quiere representar, es decir, un modelo metódico.

Este fundamental corolario de cientificismo, lógicamente exigible y aplicable a la ciencia histórica, se satisface en lo que llamamos marco histórico de referencia. El pasado ha dejado un abigarrado conjunto heteróclito e informe de información, pero dados los particulares caracteres del hecho histórico, el producto historiográfico no lo considerará como resultado de una mera crónica narrativa, pues no sería ésta una construcción científica sino que dará lugar a una historia analítica y explicativa de los fenómenos del pasado, y por tanto, científicamente y rigurosa, articulada en función de un "esquema orgánico de conjunto, de marcos analíticos globales, de presupuestos teóricos de referencia, capaces de imputar a los datos un significado de conjunto y hacer aparecer el conjunto como un todo coherente"20.

La condición dinámica del hecho histórico explica cualquier hecho del pasado como producto de los desarrollos temporales y dinamismos naturales propios que presenta el conjunto del sistema, además, de explicarse como resultante funcional de una relación de factores interdependientes en el proceso global de su desarrollo. Como resultado y a la vez producto, tiene una decisiva trascendencia proyectiva y formal, puesto que configura el discurso historiográfico necesariamente como una sucesión de sincronías. Por otra parte, el carácter pretérito y la imposibilidad de contemplación directa y reproducibilidad del hecho histórico condiciona al historiador a no poder proceder al registro directo de datos, sino que se debe valer de testimonios (escritos, orales, sonoros...), configurando precisamente la raíz de las fuentes, métodos y técnicas de investigación histórica.

La investigación del hecho histórico difiere radicalmente de la investigación en las ciencias naturales (positivas) en lo que respecta a elaborar esquemas lógicos de sus explicaciones, ya que en estas últimas son los hechos mismos los que condicionan e imponen la opción hipotética, mientras que en la Historia son hipótesis ad hoc, es decir, las que puede formular el historiador según sus propias necesidades intelectuales y sus diversas opciones personales. La única forma de comprobación válida será mediante un conocimiento inferencial (por deducción) o verificación por implicaciones. A través de tales métodos se parte de supuestos provisionales no evidentes pero probables, "construyendo" racionalmente un conocimiento a partir de consecuencias observables que se habrán producido desde intereses o necesidades sociales, siendo los propios hechos investigados los que deberán verificar las hipó-

19 COLLINGWOOD, R. G.: Idea de la Historia, México, Fondo de Cultura Económica, 1977, pág. 272.

20 ESCANDELL BONET, B.: Teoría del discurso histórico, Universidad de Oviedo, 1992, pág. 98. 
tesis instrumentales utilizadas ${ }^{21}$. Dicho de otro modo, el hecho histórico como documento supone la materia prima del historiador, comprende el dato empírico sustancial sobre el que opera el investigador del pasado. Las hipótesis del historiador serían la fórmula para aventurarse al conocimiento científico; decidir qué o cuales acontecimientos participarán en un experimento. Su propio juicio actuaría como reactivo en un tubo de ensayo que se correspondería con la síntesis final. El presente procedimiento estará caracterizado por la posesión de un marco teórico de referencia para imputar a los datos asilados un significado de conjunto, es decir, hacer aparecer el conjunto como un todo coherente.

De los indicados caracteres del hecho histórico y del itinerario cultural que expresa la lógica general del conocimiento histórico derivan en esencia todas las peculiaridades de la investigación histórica (fuentes, métodos, técnicas de investigación, particularidades epistemológicas, mecanismos causales, sistema de comprobación de hipótesis, etc.). Por consiguiente, si trasladamos estas cuestiones al debate de la investigación del Patrimonio bajo las premisas del componente historiográfico, el estudio y análisis del mismo debe ser un proceso metódico y técnico que origina el saber científico. La práctica investigadora del pasado relata lo leído en los documentos históricos y requiere ejercitarse con el concurso de tres factores esenciales:

- Una previa base de conocimiento teórico, puesto que el pasado nos ha dejado un abigarrado y fragmentado conjunto heteróclito de testimonios que pueden ordenarse y describirse cronológicamente, si bien los datos expuestos no revelarán su sentido más que cuando se articule un análisis global que confiera al conjunto una estructura informativa coherente.

- En segundo término, dado la condición pretérita del hecho histórico, únicamente el dominio del método histórico enfocado a la ejecución de un proceso inquisitorio en profundidad podrá aseverar una correcta investigación empírica.

- Por último, la instrucción en técnicas historiográficas y la capacidad deductiva personal, la perspicacia profesional y el genio literario del historiador (del arte) constituirán los únicos medios de que dispondrá éste para afrontar el posterior inventario y clasificación de la información, así como de la traducción de los resultados analíticos de la investigación a enunciados teóricos o conclusiones históricas, en pro de una eficaz comunicación historiográfica a los demás.

\section{EL POR QUÉ DE LA RE-CONSTRUCCIÓN.}

"Sucede que la memoria colectiva necesita de estímulos para pervivir. Y si un determinado motivo la sume en el olvido, toda su circunstancia se esfuma, al menos hasta que otro de distinto signo le devuelve sus motivaciones y establece las coordenadas de su resurrección"22.

21 Ibídem., págs. 104-106 y 109. 


\section{1: artículos Belén Calderón Roca}

La ciudad histórica se halla estrechamente vinculada con la tradición religiosa y desde tiempos remotos las ciudades han emergido determinadas por la religión. El hombre siempre ha sentido la necesidad de creer, ha vivido en todo momento guiado por una inclinación a buscar amparo en una serie de convicciones donde refugiarse cuando se veía azotado por los reveses de la vida, asumiendo la religión su labor de dar sentido a su existencia. Aquella misma necesidad le exigía exteriorizar sus sentimientos y a través de la arquitectura, el hombre ha materializado simbólicamente unas creencias a la vez que delimitaba un espacio que consideraba propio, mediante un hito referencial con el cual sentirse identificado. Estos vínculos materiales del individuo aislado con su medio se han hecho extensibles con el tiempo a su comunidad, creando un paisaje urbano como respuesta precisamente a esa necesidad de establecer un código de signos propio de un mismo asentamiento.

Indudablemente el encuentro con lo antiguo provoca en nosotros una gran curiosidad. Cuando nos disponemos a contemplar el Patrimonio Urbano, retrocedemos en cierta medida a aquel pasado de la ciudad tan lejano, tan quimérico... La fascinación y sugestión que suscitan aquellas vetustas imágenes está en gran medida determinado por su carácter de unicidad y singularidad. La unicidad de los acontecimientos se fundamenta de manera empírica justamente por su carácter sorpresivo, puesto que al experimentar sorpresa concebimos el acontecimiento como algo diferente a cómo suponemos que pudo ser. Esta circunstancia despierta en nosotros el anhelo de aquello que se ha perdido, y nuestra conducta desata nuestra ambición al tratar de hacernos partícipes de múltiples experiencias vitales, asimilar comportamientos humanos pretéritos con los que nos sería imposible mantener contacto si no existiesen estos vínculos materiales. De modo que cuando prima el desconocimiento de una maraña de tiempos, territorios, creencias y manifestaciones culturales que coexisten de manera complicada, estos espacios se nos antojan misteriosos, y al tiempo, atractivos. Sin embargo, el resultado de lo desconocido puede trocarse en distancia cuando la interpretación de las tradiciones y las representaciones pretéritas no se realizan de forma adecuada 23 .

Cuando el hombre toma contacto con cualquier espacio, lo visual se fusiona con lo sensorial (las sensaciones que suscita ese preciso escenario). Pero al mismo tiempo el hombre emana de sí mismo diversas emociones que de forma continuada van fundiéndose con el ambiente en su complejidad cognoscitiva, física y social, con los acontecimientos que en él se suceden, e igualmente con el resto de individuos de la sociedad en la que vive. El barrio, la plaza, la calle, o el portal son lugares de contacto humano que se convierten en un anfiteatro donde se desarrolla la representación social del hombre en sus múltiples facetas. El hombre en su camino generacio-

22 GARCÍA ATIENZA, J.: Montes y simas sagrados de España, Madrid, Edaf, 2000, pág. 113.

23 CALDERÓN ROCA, B.: "La tutela jurídica de los centros históricos: disertaciones sobre la antítesis entre teoría y práctica en base a la preservación del valor cultural", en Boletín de Arte, $n^{\circ} 25$, Departamento de Historia del Arte de la Universidad de Málaga, 2004, págs. 521-522. 
nal ha ido acotando este espacio y ha fijado unos límites para indicar su territorio. Sin embargo el espacio pertenece al hombre de la misma manera que el hombre a éste, ambos se complementan y se necesitan. Precisamente mediante esta reciprocidad perpetuada a lo largo del tiempo un espacio llega a cristalizar en un organismo histórico con personalidad propia, consigue el genius loci, que no es sino todo lo que se desprende de un lugar, la fascinación que motiva, el encanto que entraña, su esencia en definitiva. La ciudad está escrita por episodios de diversa índole y debemos escarbar en cada uno de los estratos que nos descubren nuevas claves de su estructura, su persistencia, su capacidad de integración, su utilidad y valores para conocer todo aquello relacionado con su existencia, así como con las expectativas de su vida material y simbólica. La aplicación de lo sagrado a un determinado espacio encuentra su génesis en la fijación de esos límites de los que ya hablamos, que son constituidos fundamentalmente por la arquitectura, definiéndose ésta como "la concretización del espacio existencial del hombre" que delimita, determina y representa el espacio, moldeando el paisaje adaptándose a las necesidades de quienes lo crean ${ }^{24}$. Con ella se establece el punto de referencia necesario para la confrontación del espacio y sus habitantes y por lo tanto, se genera atracción hacia éste. A partir de aquí surgirá una serie de rutas sagradas que siempre conducirán a ese hito central.

Por otra parte, las formas de la arquitectura religiosa resultan especialmente sensibles, puesto que las construcciones por sí mismas no tienen significación sagrada sino que ésta viene dada por el hombre mediante el uso que hace de ellas. Con ello simplemente venimos a explicar que el espacio sacro resulta especialmente confuso ya que en él intervienen hechos intangibles (manifestaciones cultuales) que independientemente de la arquitectura dotan de valor y significación cultural al espacio. Si pensamos por ejemplo en los antecedentes urbanísticos de una ciudad como Málaga, de profundas raíces islámicas, en la ciudad árabe la mezquita constituyó siempre el punto de referencia para aunar a la población en torno a la religión. Pero al mismo tiempo, en el mundo musulmán la vida social no tenía sentido de cara al exterior. El concepto de calle como tal no existía, y éstas, tortuosas y laberínticas, no constituían un espacio de recreo ni servían de lugar de reunión, sino de eje comunicador entre diferentes zonas. La búsqueda de la intimidad y de la organización de la población se efectuaba en el interior de las viviendas, un lugar íntimo, casi secreto que convertía la casa en un santuario, a juzgar por las afirmaciones del Corán 25 . En cambio, la estructura de la ciudad cristiana se estableció de manera diferente.

24 MORALES, J.: "La construcción del olvido. Memoria, historia, proyecto", en AA.VV.: Arquitectura y Patrimonio: Memoria del futuro. Una reflexión sobre la relación entre Patrimonio y Arquitectura, Cádiz, Instituto Andaluz de Patrimonio Histórico, Junta de Andalucía, 1994, pág. 12

25 "Y cuando hicimos de la Casa (la Káaba) lugar de reunión y de refugio para los hombres. Y: ¡¡Haced del lugar de Abraham un oratorio!'. Y concertamos una alianza con Abraham e Ismael: que purificaran Mi Casa para los que dieran las vueltas, para los que acudieran a hacer un retiro, a inclinarse y a prosternarse", "...los que te vocean sin esperar a que salgas de él son insensatos, porque faltan el respeto a Dios...". BERGUA, J. B. [trad. y notas]: El Corán. Madrid, 1975 , suras $2^{\circ}, 125,4^{\circ}$ y $5^{\circ}$. 
Las calles y las plazas fueron trazadas previamente y los edificios fueron ocupando un espacio establecido en función de unas necesidades impuestas por la sociedad, que las demandaba como hábitat colectivo. Según Fernando Chueca la ciudad española se originó en gran parte, tras la conciliación de la metrópoli clásica y la urbe islámica, culminando en la característica ciudad-convento del barroco como fruto de las modificaciones efectuadas sobre la morfología de la islámica existente26.

Hemos hablado en líneas anteriores de la importancia de la arquitectura vernácula para la vida cultural de la comunidad a la que pertenece y a colación, parece pertinente destacar que de entre la mayor parte del patrimonio histórico monumental, sobresalen por su especial interés y cuantía los edificios religiosos. Un incalculable número de ciudades, pueblos, aldeas o parajes aislados han albergado a lo largo de los siglos un gran conjunto arquitectónico formado por catedrales, iglesias, parroquias, monasterios, ermitas, capillas, etc. Su valor lo adquieren no sólo por su condición de instrumentos específicos para el desarrollo de la vida espiritual y litúrgica al servicio de la comunidad, sino además, por representar el principal exponente cultural que durante siglos han proporcionado el componente definidor de diversas sociedades occidentales como la española. Además del inherente valor histórico-artístico y arqueológico que ostentan las construcciones en sí mismas, los edificios religiosos cobijan en muchos casos el más nutrido arsenal de bienes muebles y patrimonio documental quizás existente en las ciudades.

Este patrimonio cultural eclesiástico desde siempre ha ostentado un valor social, entrañando connotaciones eminentemente pedagógicas, pues fue generado y conservado preferentemente para el culto y la difusión de la fe religiosa. Desafortunadamente las diversas vicisitudes por las que ha atravesado el enorme caudal sacro edificado a lo largo de la Historia -desamortización, guerras, catástrofes naturales, saqueos, incendios, abandono intencionado...- han hecho que este legado sea cada vez más reducido. Las dificultades económicas con las que ha tropezado la Iglesia para la conservación de su acervo cultural ha radicado principalmente en el enorme volumen del mismo y la improductividad que lo caracteriza, lo que ha originado la destinación continua de dispendios para su custodia y mantenimiento, a pesar de que esta institución ha visto alimentadas constantemente sus pertenencias mediante las donaciones de sus fieles, en un principio a través de ofrendas de diversos bienes (pan, cera...), más tarde mediante el pago de diezmos y en otros casos con la donación directa de tierras, fincas y edificios ${ }^{27}$. En este sentido las órdenes monásticas fueron verdaderos focos de cultura y riqueza artística que conformaron un

\footnotetext{
26 La ciudad cristiana "plagia" la privacidad musulmana, infiriéndola al interior de grandes parcelas (los conventos) que albergan en su interior tanto edificios como calles o pasadizos. CHUECA GOITIA, F.: Breve historia del urbanismo, Madrid, Alianza Editorial, 1970, pág. 15.

27 En el caso de las órdenes religiosas el patrimonio se incrementaba permanentemente mediante las dotes, ya fuese por medio de la donación de inmuebles o de tierras de labor, requisito indispensable para acceder a la orden y sufragar su perpetuación. Vid. RODRÍGUEZ MARÍN, F. J. (2000): Málaga conventual. Estudio histórico, artístico y urbanístico de los conventos malagueños, Málaga, Arguval, Cajasur, 2000, págs. 21-41.
} 
patrimonio eclesiástico concebido actualmente para ser exhibido, contemplado y estudiado, aunque inicialmente surgiese de los tributos ofrecidos para sostener el culto divino ${ }^{28}$. Gran parte de los bienes inmuebles conservados lograron perpetuar su fisonomía y sus características físicas en mayor o menor medida, manteniéndose en sus enclaves originarios. La razón podemos encontrarla en la permanente utilización de ese Patrimonio para los mismos fines para los que fue creado: su función cultual, que continúa activa incluso aún en nuestros días.

Por otra parte, el arte ha estado siempre íntimamente relacionado con la religión, y la contemplación del objeto artístico concebido para la exaltación de la fe despierta el sentimiento religioso y a la vez, suscita la valoración de la obra de arte en sí misma, originando que en los últimos tiempos la atracción por el patrimonio religioso se haya visto imbuida además de cierto laicismo, denotando fundamentalmente anhelos de erudición artística y cultural. En el caso de la arquitectura, la sugestión se incrementa respecto a los bienes muebles debido al amplio campo de actuación que supone para el arte, manifestándose en sus características de esteticismo, monumentalidad, complejidad estructural y espacial, pluralidad de materiales, etc. Los edificios religiosos como expresión simbólica de espacios o hitos ostensibles y tangibles de la Iglesia están dotados de unas particulares y específicas características. Son lugares privilegiados necesarios para expresar la fe. La mayor parte ellos deben su origen a las necesidades de cada lugar y cada comunidad ${ }^{29}$ y se han adaptado al estilo artístico predominante en cada época ${ }^{30}$.

Resulta evidente que las construcciones religiosas mantienen un particular vínculo con su entorno en cuanto a las características físicas y espaciales, tradiciones y al carácter singular de los habitantes. Hubo tiempos en que la Iglesia patentizaba un predominio espiritual y preceptor sobre una sociedad eminentemente religiosa. Ya desde la Edad Media la Iglesia marca la condición de Civitas Dei (ciudad de Dios) a las ciudades, donde los templos constituyen núcleos referenciales para la construcción y organización de los agregados urbanos. Durante la Reconquista obedeciendo a programas de renovación cultual y aniquilación de devociones como la musulmana o la hebrea, la ocupación simbólica del espacio mediante nuevas construcciones y demarcaciones se convierte en una de las principales armas de lucha contra la herejía. En el Renacimiento se afianza la tendencia del esteticismo en la edificación de templos que dominaban el paisaje de las aldeas y poblados, donde podían divisarse con nitidez las siluetas de los campanarios en el horizonte y en los

28 IGUACEN BORAU, Mons. D.: La Iglesia y su patrimonio cultural, Madrid, Editorial Edice, 1984, págs. 53-55 29 Las primeras comunidades cristianas no tenían necesidad de construir templos, bastaba un recinto donde poder reunirse para celebrar la liturgia pero desde finales del siglo II se inicia un proceso de sacralización del espacio que culmina a finales del siglo III con la instauración de la filosofía pagana del templo, y a partir de edicto de Milán en el año 313, con la basílica paleocristiana quedará institucionalizado el primer modelo de templo cristiano. GÓMEZ SEGADE, J. M.: Función y símbolo en la arquitectura eclesial del siglo XX, Granada, Universidad de Granada, 1985, págs. 349-354.

30 JUNYENT, E.: La Iglesia. Construcción, decoración, restauración, Barcelona, Editorial Balmes, 1939, págs. 13-19. 
núcleos urbanos de grandes dimensiones. La parroquia era el eje alrededor del cual se estructuraban los barrios y giraba la vida de la población. Posteriormente en el marco de la Contrarreforma durante el siglo XVII, se incrementaron las competencias y la autoridad de la Iglesia y la incitación al culto apoyada por la monarquía favoreció la proliferación de ermitas, oratorios y capillas callejeras que junto a los edificios conventuales ocuparon vastas porciones de terreno en las ciudades, dotando a los espacios urbanos de una imagen sacralizada y al mismo tiempo, determinaron la estructura urbanística básica de la mayor parte de los cascos antiguos españoles. Con el Barroco la arquitectura religiosa en sus múltiples manifestaciones fue usurpando velozmente espacio en las ciudades y el enorme poder económico y social del clero en el antiguo Régimen condujo a la Iglesia a ocupar los solares y edificios más relevantes ${ }^{31}$.

Como si de piezas de un puzzle magníficamente preconcebido se tratara, los inmuebles iban insertándose en un contexto territorial dotado de una especial fisonomía mediante la singular disposición de la arquitectura doméstica anónima, los trazados de las calles y la alineación de plazas eran modificados paulatinamente por la aparición de un nuevo convento, parroquia o ermita. Mediante desfiles procesionales, conmemoraciones o funerales ${ }^{32}$ y en definitiva, en toda clase de ceremoniales cargados de teatralidad, se hacía un uso público y activo de ese espacio urbano que se convertía en un iter sacrum (recorrido sagrado). Se unieron parroquias, conventos, iglesias y edificios civiles principales, constituyendo los segmentos más frecuentes de las procesiones que incrementaban más si cabe la impronta religiosa de las ciudades $^{33}$. Igualmente relacionadas con los entornos parroquiales se encontraban las cofradías, forma de religiosidad popular que dedicaba culto a la advocación de Cristo o la Virgen, y que aún permanece activa en nuestros días ${ }^{34}$. Estas agrupaciones estaban muy vinculadas a las parroquias o conventos que les proporcionaban

31 Se dogmatiza el concepto de monumentalidad aplicada a los templos y a las ciudades, culminando con las aportaciones de los siglos XIX y XX un significativo proceso de agregación cultural enormemente rica y diversa. CAMACHO MARTÍNEZ, R.: "La religiosidad y el arte. La arquitectura", en MORALES FOLGUERA J. M.[dir.]: Málaga en el siglo XVII, Málaga, Ayuntamiento, 1898, págs. 52-54.

32 Los cementerios -a partir del s. V- se emplazaban junto a los ábsides de los templos, a espaldas de las parroquias y conventos, puesto que de ellos solía partir el séquito formado por familiares, amistades y vecinos junto al clero de la parroquia correspondiente, que acompañaban al difunto en un recorrido por las calles de la ciudad donde se daban cita los despliegues lumínicos que mediante velas, cirios y antorchas acrecentaban el tenebrismo de aquella lúgubre y tétrica atmósfera. REDER GADOW, M.: Morir en Málaga. Testamentos malagueños del siglo XVIII, Málaga, Universidad de Málaga, Diputación Provincial, 1986, págs. 92-94 y 110-114.

33 Cualquier celebración tenía su hueco en la vía pública: la finalización de las obras de un templo entrañaba recitales de música y sermones, exequias fúnebres, así como las arquitecturas efímeras, que sirvieron de escenario incomparable para la celebración de las festividades religiosas de Semana Santa, Corpus Christi, onomásticas reales o canonizaciones. CALDERÓN ROCA, B.: "Más allá... op. cit.

34 Datan de época medieval, pero a raíz de la Reconquista se extendió su práctica habitual. Vid. LLORDÉN, A. y SOUVIRÓN, S.: Historia documental de las cofradías y hermandades de Pasión de la ciudad de Málaga, Málaga, 1969, pág. 19; v. a. SÁNCHEZ LÓPEZ, J. A.: Muerte y cofradías de pasión en la Málaga del siglo XVIII : La imagen procesional del Barroco y su proyección en las mentalidades, Málaga, Diputación Provincial, 1990. 
cobijo y de ellos salían en procesión las imágenes de culto por diversos itinerarios de la ciudad, infiriendo un carácter particular a los barrios donde se encontraban ubicadas $^{35}$. Por ejemplo, el origen de los vía crucis y sacromontes se remonta al siglo $\mathrm{V}$, con la reproducción de mano de San Petronio de una nueva Jerusalén en la ciudad de Bolonia 36 . Ambos mantienen en común el concepto de "peregrinación de sustitución" y su divulgación en Europa tuvo lugar en el siglo XV, después de que distintos viajeros visitasen ciudades santas y recorrieran aquellos lugares de pasión anotando detalles de interés. A su regreso portaban recuerdos y reliquias que pudiesen atestiguar la verosimilitud del camino recorrido por Cristo en su pasión ${ }^{37}$. Estas prácticas religiosas adquirieron una amplia difusión tras la Contrarreforma (15601648) pues sin la necesidad de desplazamiento a Palestina, se le proporcionaba al fiel una reproducción de Tierra Santa en su entorno más próximo. A través de la procesión, el fiel efectuaba una aproximación a los padecimientos físicos de Cristo y experimentaba la meditación de la penitencia y la redención a través las indulgencias concedidas. Tras la conquista de la España musulmana por los Reyes Católicos, las procesiones de carácter penitencial rememoradas en las Estaciones del Calvario, se convirtieron en vías para que los conversos dieran muestra pública de su arrepentimiento y purgasen sus pecados, siendo redimidos por el sacrificio de la muerte de Jesucristo en la cruz. Posteriormente este culto se generalizó a todos los fieles cristianos, realizándose todos los viernes del año.

Independientemente de su prolongación física en el tiempo, los testigos corpóreos de la ciudad histórica correctamente aprehendidos crean un nexo de familiaridad y suscitan un sentimiento de satisfacción en el sujeto, en su toma de conciencia espiritual, motivado por su adhesión al ambiente al que se encuentra adscrito, estableciendo así una vinculación entre el hombre y los testigos físicos que forman el Patrimonio de la ciudad histórica. Sólo así podrá éste otorgarles cualidades, méritos y valor. Por desgracia, y en demasiadas ocasiones, la composición y mucho menos, la consolidación de la identidad cultural de la ciudad histórica no se ha producido jamás. Por ello es necesaria una re-composición que no consiste en reconstruir algo, sino más bien constituirlo desde cero. Sin duda, es la comunidad en su ejercicio de elección la que debe aprehender la ciudad histórica; conocerla, diferenciarla, asimilar las relaciones estructurales mediante un proceso de separación de los elementos particulares específicos de la totalidad que la conforma. Este proceso

\footnotetext{
35 N. B.: Aunque no estaban formadas por un colectivo homogéneo, la pertenencia a una institución de estas características determinaba la forma de vida de los individuos en su entorno social.

36 Los sacromontes, más plenamente inmersos en una naturaleza agreste y por lo general, promovidos por órdenes religiosas, se diferencian de los Vía Crucis por su ubicación en las afueras y cercanías de las ciudades, con frecuencia coronando un cerro junto a uno de sus caminos (aunque no necesariamente) y en que su promoción recaía con frecuencia en un personaje noble o destacado.

37 RODRÍGUEZ MARÍN, F. J.: "El Monte Calvario: la vía sacra de Málaga", en Religiosidad Popular en España. Actas del Simposium II, San Lorenzo del Escorial, 4-IX-1997, Col. Instituto Escurialense de Investigaciones Históricas y Artísticas, n 9, RCU Escorial-Mª Cristina, 1997, pág. 605.
} 
exige una reflexión, un juicio crítico, y dicho juicio constituye un particular recorte en el continuum de los hechos y los conocimientos, recorte en el cual el ordenamiento y la selección de los objetos recae la esencia misma del Patrimonio. La lectura de estas piezas no tendrá sentido si son segregadas de la globalidad de la ciudad, y es el reconocimiento del proceso de interrelaciones de la parte con el todo en su carácter abierto e inconcluso el vehículo que otorgará significación a la realidad de la ciudad histórica. Se trata en definitiva, de re-componer su identidad cultural.

\section{Algunas reflexiones.}

"Cuando la ciudad comenzó a salir de su letargo..."38.

No cabe duda de que la ciudad funciona como espejo de la representatividad de un determinado territorio, y el valor del Patrimonio se forja en íntima conexión del individuo con el territorio en el que nace y se desarrolla parte o la totalidad de su existencia. Para facilitar su comprensión hemos de conocer la dimensión que adquieren los lugares sagrados en sociedades donde la religión ha sido el eje preceptor a partir del cual se ha materializado gran parte de la historia a través de la arquitectura. La religión impregnaba profundamente la vida de los individuos y los lugares sagrados expuestos en este trabajo como un ejemplo, se entienden como espacios dotados de cualidades específicas que guardan relación con algo superior, y que por ello deben provocar la motivación colectiva de los sujetos.

En la actualidad somos deudores de reconstrucciones que han favorecido la fragmentación de la imagen urbana, la distorsión de la propia percepción e interpretación de la ciudad y de sus bienes patrimoniales y la disolución del sentimiento de identificación de la comunidad con su territorio. En casos como éste la reconstrucción material de un Bien Cultural es vinculante a la re-construcción de la memoria colectiva, pues la memoria colectiva se deforma, se desmiembra... Y resulta una satisfacción destacar que la administración pública haya recurrido en las últimas décadas a especialistas en Patrimonio Cultural para la elaboración de criterios que permitan a priori, la identificación del Bien, su reconocimiento por parte de la comunidad, y a posteriori, fijar el sentimiento de adhesión al mismo.

La empatía hacia nuestro Patrimonio está determinada por su carácter de elemento único y singular, pero gran parte de la sociedad malagueña no se reconoce en el territorio porque está habituada a aproximarse al Patrimonio en clave monumental, y precisamente, la importancia de algunos lugares reside en sus connotaciones histórico-religiosas, unidas a la tradición y a lo popular. Pero aunque el ciudada-

38 Como ya cita Eduardo Asenjo, nos referimos al letargo urbanístico en que se sumió la ciudad de Málaga entre las décadas de los 60 y 80 del siglo XX con las operaciones de cirugía urbana que se acometieron, proliferando las demoliciones y sustituciones del tejido urbanístico histórico. ASENJO RUBIO, E.: "Ciudad y color en la rehabilitación de la imagen urbana. El discurso fragmentado", en ASENJO RUBIO, E. y CAMACHO MARTÍNEZ, R.: Las ciudades..., op. cit., pág. 125. 
no se encuentre inmerso en ritos y prácticas populares desde siempre, no logra en ocasiones identificarse con su Patrimonio, es decir, no lo reconoce como algo propio, y a ello hay que añadir que éste no haya adquirido las herramientas y la sensibilidad necesarias para abordar la mirada hacia el pasado de una manera correcta. No obstante, los bienes inmateriales presentes en la ciudad histórica son en esencia acciones, conductas..., caracterizadas por una determinada relevancia cultural. Sin embargo, ante la profusión de bienes y la indeterminación de los conceptos que los definen, y puesto que la Ley $16 / 85$ de 25 de junio de Patrimonio Histórico Español no introduce una aclaración precisa sobre aquello que es relevante, se plantea entonces la ineludible necesidad de interpretarlos conforme a un principio metodológico acorde con su carácter espinoso.

Llegados a este punto, la memoria popular resulta bastante limitada y no dispone de los recursos para alcanzar continuidad histórica. La memoria, tanto visual como escrita, es profundamente subjetiva e indiferente a las reconstrucciones de conjunto. Se precisa realizar múltiples miradas hacia el pasado desde el presente, y efectuar un proceso de re-lectura historiográfica que filtre los acontecimientos y nos exhiba el hecho histórico fundado sobre una verificación crítica en cuanto la espontaneidad de la memoria que lo ha producido. De este modo, el recuerdo se encontrará permanentemente sometido a la reelaboración derivada del juicio colectivo y de la influencia del criterio historiográfico. Ello permitirá recuperar los propios orígenes, así como aprehender el caudal histórico de los pueblos vigorizando la identidad social y configurando así la memoria cultural, que no histórica.

Comunicar significa etimológicamente poner en común, y una situación no puede ser plenamente aprehendida y compartida si no consideramos las interrelaciones que la caracterizan. A juzgar por cómo sea la experiencia cognoscitiva, según será el juicio personal emitido, y la valoración y apreciación que se desprenda de éste. Las mencionadas circunstancias de percepción junto con estos condicionantes inducirán a la reflexión, a la aprehensión y a la subsiguiente comunicación de lo percibido. En ello radica la identificación del sujeto con su entorno. En virtud de estas afirmaciones declaramos que no deben existir períodos cerrados al análisis de la ciudad histórica. Cualquier período o fenómeno de la historia que afecte a la construcción de una biografía de un espacio cultural, sea cual fuere su tipología debe estar en revisión permanente. 
